\section{OPEN ACCESS}

Edited by:

Gilles Benichou,

Massachusetts General Hospital,

USA

Reviewed by:

Gianfranco Pittari,

Hamad Medical Corporation, Qatar

Raphael Carapito,

University of Strasbourg, France Rex Neal Smith,

Harvard Medical School, USA

James I. Kim,

Harvard Medical School, USA

*Correspondence:

Anil K. Chauhan

chauhana@slu.edu

Specialty section:

This article was submitted to Alloimmunity and Transplantation, a section of the journal

Frontiers in Immunology

Received: 31 December 2015

Accepted: 17 May 2016

Published: 01 June 2016

Citation:

Chauhan AK (2016) Human CD4+ T-Cells: A Role for

Low-Affinity FC Receptors.

Front. Immunol. 7:215.

doi: 10.3389/fimmu.2016.00215

\title{
Human CD4+ T-Cells: A Role for Low-Affinity Fc Receptors
}

\section{Anil K. Chauhan* \\ Division of Adult and Pediatric Rheumatology, Saint Louis University School of Medicine, St. Louis, MO, USA}

Both lymphoid and myeloid cells express Fc receptors (FcRs). Low-affinity FcRs engage circulating immune complexes, which results in the cellular activation and pro-inflammatory cytokine production. FcRs participate in the internalization, transport, and/or recycling of antibodies and antigens. Cytosolic FcRs also route these proteins to proteasomes and antigen-presentation pathways. Non-activated CD4+ T-cells do not express FcRs. Once activated, naive CD4+ ${ }^{+}$-cells express FcyRllla, which, upon IC ligation, provide a costimulatory signal for the differentiation of these cells into effector cell population. FcyRIIlla present on $\mathrm{CD}^{+}{ }^{+} \mathrm{T}$-cell membrane could internalize nucleic acid-containing ICs and elicit a cross-talk with toll-like receptors. Fc $\gamma$ RIIlla common $\gamma$-chain forms a heterodimer with the $\zeta$-chain of T-cell receptor complex, suggesting a synergistic role for these receptors. This review first summarizes our current understanding of FcRs on CD4 ${ }^{+}$ T-cells. Thereafter, I will attempt to correlate the findings from the recent literature on FcRs and propose a role for these receptors in modulating adaptive immune responses via TLR signaling, nucleic acid sensing, and epigenetic changes in CD4+ T-cells.

Keywords: Fc-receptors, T-lymphocytes, autoimmunity, toll-like receptors, epigenetics

\section{INTRODUCTION}

Immunoglobulin $\mathrm{Fc}$ receptors (FcRs) are expressed by many immune cells, and these receptors induce many diverse biological functions. Activating- and inhibitory-FcRs are expressed as pairs, and they govern the outcome of an immune response. Sandor and Lynch very early on showed that T-cell receptor (TCR)-activation results in the induced expression of $\mathrm{F}_{c} \alpha \mathrm{R}, \mathrm{F} c \mu \mathrm{R}$, and $\mathrm{Fc \in R}$ in $\mathrm{CD} 4^{+}$ T-cell clones (1). FcR common $\gamma$-chain (FcR- $\gamma$ ) is the ITAM-bearing signaling unit of FceRI, Fc $\gamma$ RI, and Fc $\gamma$ RIIIa (2). FcR- $\gamma$ chain independently supports the complete development of peripheral $\mathrm{CD}^{+}$T-cells in mice lacking the TCR $\zeta$-chain (3-5). The FcR- $\gamma$ chain forms a heterodimer with the $\zeta$-chain of TCR in CD4 ${ }^{+}$T-cells. Membrane-FcyRIIIa in these cells can signal using the $\zeta-\zeta$ chain, $\gamma-\gamma$ chain homodimers, or $\zeta-\gamma$ chain heterodimers. $\zeta$-chain deletion is not a lethal event for $\mathrm{CD} 4^{+} \mathrm{T}$-cell development, suggesting an alternative-signaling pathway using the FcR- $\gamma$ chain. In $\mathrm{CD}^{+}{ }^{+}$T-cells, the FcR- $\gamma$ chain engages Syk kinase for signaling (6). Syk is a ZAP-70 homolog that successfully substitutes for ZAP-70 kinase activity (7). Upon phosphorylation by FcR- $\gamma$ chain, Syk provides a distinct and a stronger signal than the ZAP-70- $\zeta$-chain of TCR complex (7). NK T-cells express both the $\zeta$-chain and FcR- $\gamma$ chain. Both of these signaling proteins associate with Fc $\gamma$ RIIIa in human NK T-cells; however, in mice, it is only the FcR- $\gamma$ chain that can associate with Fc $\gamma$ RIII (8). In NK T-cells, the increased expression of $\zeta$-chain downregulates Fc $\gamma$ RIIIa expression (9). These studies suggest a regulatory role for these signaling proteins.

Thus far, a role for low-affinity FcRs in $\mathrm{CD}^{+}{ }^{+} \mathrm{T}$-cell responses has not been envisioned, despite a number of early studies supporting the presence of these receptors on such cells. Of special interest is 
how positive costimulation from the FcyRIIIa-pSyk signal could alter $\mathrm{CD} 4^{+} \mathrm{T}$-cell responses, which, thereby, contribute to tolerance breakdown $(10,11)$. Systemic lupus erythematosus (SLE) is a classical autoimmune manifestation and is a good model to address these questions since the disease pathology is driven by ICs, the primary ligand for FcyRIIIa (12). In addition, SLE is associated with a hyperactive $\mathrm{T}$-cell response and the presence of autoantibodies that form ICs. Enhanced Th1 and Th17 CD4 ${ }^{+}$ T-cell responses are a hallmark of SLE pathology. An indirect role for FcRs in the Th1 response has also been proposed (13). ICs are present on the membrane of subcapsular sinus macrophages and are not phagolysed. Intact ICs are transferred from the plasma membrane of antigen-presenting cells (APCs) to the B-cell surface (14-16). In germinal centers (GCs), this makes ICs available on APC and B-cell plasma membranes, which are accessible to participate directly in the $\mathrm{CD} 4^{+} \mathrm{T}$-cell differentiation upon contact with naive $\mathrm{CD} 4^{+} \mathrm{T}$-cells (Figure 1). Furthermore, ICs could also facilitate formation of cyto-conjugates of $\mathrm{CD} 4^{+} \mathrm{T}$-cells with other cells expressing FcRs (Figure 1).

The ICs formed by nucleic acids (DNA/RNA) and autoantibodies are pathogenic and trigger TLR signaling and nucleic acid sensing (17). In SLE, Fc $\gamma$ RIIa internalizes DNA/RNA-ICs in plasmacytoid dendritic cells (pDCs), which result in a type 1 IFN response, a key driver of SLE disease pathology (18). Even though $\mathrm{CD}^{+}{ }^{+}$T-cells demonstrate TLR signaling in an autoimmune response, the mechanisms for the delivery of nucleic acids to cytosol are unknown $(19,20)$. Nucleic acid sensors in innate cells drive IFN responses that contribute to autoimmune pathology. Data are emerging that link both TLR proteins and DNA sensors in the development of CD4 ${ }^{+} \mathrm{T}$-cell effector responses (21-23).

This review will summarize the literature supporting the presence of FcRs on $\mathrm{CD}^{+}{ }^{+} \mathrm{T}$-cells, and further makes a case for FcyRIIIa-pSyk signaling in the modulation of TLR responses and epigenetic changes in the human peripheral $\mathrm{CD} 4^{+} \mathrm{T}$-cells.

\section{FcRs ON CD4 ${ }^{+}$T-CELLS}

The expression of FcRs and their role in $\mathrm{CD} 4^{+} \mathrm{T}$-cell-mediated adaptive immune responses is controversial. Several groups have argued for the lack of low-affinity FcRs on CD4 ${ }^{+}$T-cells $(2,24)$. This is likely true for non-activated $\mathrm{CD}^{+} \mathrm{T}$-cells, and these cells do not contribute to the disease pathology. However, once activated, $\mathrm{CD} 4^{+} \mathrm{T}$-cells express robust amounts of FcyRIIIa receptors, which is an activation-induced response (10). The activation signal that triggers the expression of F $\gamma$ RIIIa in activated cells remains unknown. Fc $\gamma$ RIIIa was initially reportedly observed in a small number of peripheral T-cells in healthy individuals $(1,25)$. Upon binding to FcRs on T-cells, IgM triggers a helper function, while ICs binding provides a suppressor function (26). Two previous studies have also shown an immunoregulatory role for FcR-bearing T-cells in a B-cell-mediated immune response $(27,28)$. A close relationship between FcR expression and cellular

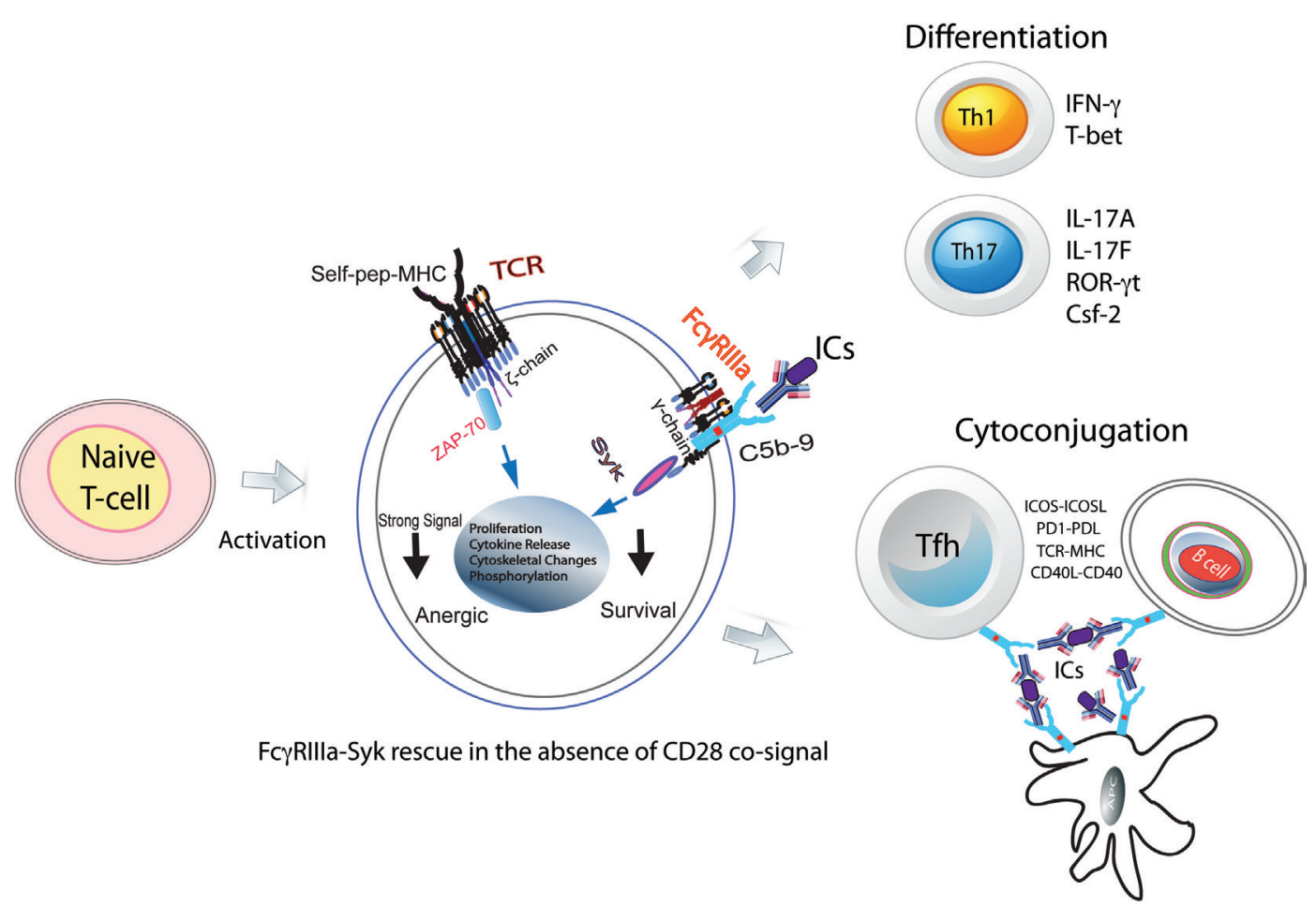

FIGURE 1 | Fc $\gamma$ RIIIa-pSyk signal in CD4+ T-cell responses. Activated naive CD4+ T-cells express FcyRIlla and provide a costimulatory signal. In the absence of CD28 costimulation, FcyRIlla ligation by ICs rescues naive CD4+ T-cells from becoming anergic. These cells show Syk phosphorylation, proliferation, cytoskeletal changes, and cytokine production. In the presence of instructive cytokine signals, these cells differentiate into Th1, Th2, and Tfh cells. In GCs, FcRs via ICs will hold together Tfh, B-cells, and FDCs forming stable cyto-conjugates. 
activation via the CD3-TCR complex was also documented (28). A stringent and narrow window during which $\mathrm{FcRs}$ are expressed on $\mathrm{CD} 4^{+} \mathrm{T}$-cells suggest a possible regulatory role for $\mathrm{FcRs}$ in adaptive immune responses, and FcR signaling may serve as a checkpoint for the development of T effector cells (29). FcR and TCR comigrate on the T-cell membrane, suggesting a synergism in signaling pathways $(1,30,31)$. FcR preferentially colocalizes with TCR into the zone of contact formed between B- and T-cells during cognate-driven cyto-conjugation (1). In trogocytosis, $\mathrm{CD} 4^{+} \mathrm{T}$-cells capture both external membrane FcyRIIIa and FcR$\gamma$ chain from the APC expressing Fc $\gamma$ R. However, this receptor transfer/capture of FcRs by T-cells is not capable of triggering a functional response (32). FcyRIIIa-mediated signaling in NK $\mathrm{T}$-cells differs from $\mathrm{CD} 4^{+} \mathrm{T}$-cells for the production of cytokines, which further suggest a divergent role for FcR in $\mathrm{CD} 4^{+} \mathrm{T}$-cells (33). Sandor and Lynch proposed an "avoidance hypothesis," where a signal in T-cells via FcyRIII might occur in the presence of antigens and specific antibodies (1). Naive CD4 ${ }^{+}$T-cells activated via ICs ligation of Fc $\gamma$ RIIIa show a limited clonal expansion, suggesting a potential contribution from antigenic peptides in the ICs. ZAP-70-deficient patients express high levels of Syk, which is activated from FcR- $\gamma$ chain phosphorylation, and it plays a distinct role in transducing TCR-mediated signal (34). These findings suggest a role for FcyRIIIa signaling via Syk (Figure 1). Syk is a key player in $\mathrm{CD}^{+} \mathrm{T}$-cell activation in SLE and is currently a therapeutic target $(35,36)$.

\section{FcRs AND T-CELL RESPONSES}

In order for naive $\mathrm{CD} 4^{+} \mathrm{T}$-cells to differentiate into effector cells, it requires two signals: (1) engagement of TCR by peptide-MHC and (2) a cosignal from CD28 upon the ligation by CD80/ CD86 expressed by APCs (37). A third signal from cytokines determines whether these cells differentiate into effector Th1, Th2, Th17, or regulatory T-cells (Treg) cells. These populations maintain and regulate immune homeostasis. Both Th1 and Th17 cells cause and sustain tissue damage, while Tregs suppress these pro-inflammatory cells. Some of the early studies have implicated FcRs in the development of suppressor T-cells, now recognized as Tregs (26). Thus, it is important to recognize the role of Fc $\gamma$ RIIIa signal as an additional positive costimulatory signal for $\mathrm{CD}^{+}$ T-cell differentiation.

The secondary adaptive immune responses are fast and robust due to rapid expansion of antigen-specific lymphocytes. FcRs facilitate these responses by binding to ICs formed by affinitymatured autoantibodies against autoantigens. In autoimmunity, aberrant $\mathrm{CD} 4^{+} \mathrm{T}$-cell responses are frequently observed, which are accompanied by autoantibody production and the IC formation. $\mathrm{CD} 3$ ligation in the absence of $\mathrm{CD} 28$ signal makes naive $\mathrm{CD} 4^{+} \mathrm{T}$-cells anergic. However, in an autoimmune background, naive $\mathrm{CD} 4^{+} \mathrm{T}$-cells bypass the $\mathrm{CD} 28$ signal requirement for activation (Figure 1). The underlying mechanism for this activation in the absence of CD28 signal is unknown (38). Unlike mice, where naive $\mathrm{CD} 4^{+} \mathrm{T}$-cells are produced in the thymus, in humans, $90 \%$ of these cells are produced in the periphery from proliferation (39). Thus, a likely scenario is that, in humans, peripheral $\mathrm{CD}^{+} \mathrm{CD} 45 \mathrm{RA}^{+}$(naive) T-cells have encountered antigen in the periphery and hence are different than those observed in mouse (39). In multiple sclerosis, differences in naive $\mathrm{CD}^{+} \mathrm{T}$-cell biology, notably of TCR and TLR signaling, have identified patients prone to more rapid conversion to secondary progression (40). Nano-LC/MS/MS analysis of ICs obtained from SLE patients show the presence of 40-250 antigenic peptides. What role these IC peptides play in the T-cell activation is not clear (41). Human naive $\mathrm{CD} 4^{+} \mathrm{T}$-cells activated in vitro by the suboptimal engagement of $\mathrm{CD} 3$ and costimulated either via CD28 cosignaling or with ICs in the presence of non-lytic C5b-9 induce FcyRIIIa expression (10). Upon Fc $\gamma$ RIIIa engagement by SLE-ICs, these cells produce high amounts of IFN- $\gamma$ and IL-17A (11). The Fc $\gamma$ RIII-mediated production of IFN- $\gamma$ is also observed in NK T-cells (9). Several mechanisms contribute to the peripheral tolerance breakdown, which results in an autoimmune response (42). TCR signal strength is one contributor to tolerance breakdown. Fc $\gamma$ RIIIa can provide an additional positive signal to the TCR for overcoming the threshold for tolerance breakdown. Thus, specific inhibition of FcrRIIIa signal in $\mathrm{CD}^{+} \mathrm{T}$-cells provides an attractive therapeutic target. Costimulatory pathways influence the outcome of T-cell stimulation and are central to the maintenance of immune tolerance (42). In the early phase of antigenic challenge from pathogens or self-antigens, activating cosignals CD28 and ICOS drive an immune expansion. Once the threat from the invading pathogens is over, the immune contraction phase is initiated by the appearance and expansion of the negative costimulatory proteins PD1 and CTLA4. In an autoimmune response, the Fc $\gamma$ RIIIamediated signal, which is an additional positive ITAM signal, can drive immune expansion. This will lead to perpetual expansion of the immune response such as that observed in autoimmunity. Syk phosphorylation is observed in those SLE CD4 $4^{+} \mathrm{T}$-cells that also produce IFN- $\gamma$ and IL-17A cytokines (11). Fc $\gamma$ RIIIa cosignaling drives the differentiation of naive $\mathrm{CD} 4^{+} \mathrm{T}$-cells into $\mathrm{Th} 1$, Th17, and Tfh effector populations $(10,11,43)$. The Th17 cells produced by an FcyRIIIa signal show markers of terminal differentiation that are associated with a pathogenic Th17 population (11). In vitro, FcyRIIIa ligation by ICs on naive $\mathrm{CD} 4^{+} \mathrm{T}$-cells induces ICOS expression both in human and mouse cells. ICOS ${ }^{+} \mathrm{CD}^{+}$ T-cells in SLE patients bind to labeled ICs, suggesting Fc $\gamma$ RIIIa coexpression (11). However, cells expressing high levels of PD $1^{\text {high }}$ do not show pSyk, suggesting a role for PD1 in immune contraction via SHIP2 by dephosphorylating pSyk (11). IC formation is observed in several other disease pathologies, including cancer and infections. Past and recent literature suggests that Fc $\gamma$ RIIIa is a crucial player for $\mathrm{CD} 4^{+} \mathrm{T}$-cell responses during autoimmunity. In future, recognizing the precise mechanism of how Fc $\gamma$ RIIIamediated signaling in $\mathrm{CD}^{+} \mathrm{T}$-cells alters the adaptive immune responses will be critical for developing therapies that target $\mathrm{CD}^{+}{ }^{+} \mathrm{T}$-cell membrane proteins such as CTLA4, PD1, TLRs, and nucleic acid sensors.

\section{CROSS-TALK BETWEEN TLRs AND FcRs}

TLR-dependent T-cell activation is observed in autoimmunity (19). The presence of FcRs on activated human $\mathrm{CD} 4^{+} \mathrm{T}$-cells raises the possibility of their coengagement with either TCR or TLRs for signaling. Upon ligand engagement, TLRs trigger 
homo-or hetero-dimerization and recruit adaptor proteins to activate downstream signaling and transcriptional activation (44). Distinct signaling by synergistic engagement and crosstalk between FcRs and TLRs in immature DCs promote a Th17 response $(45,46)$. Such cross-talk between FcRs and TLRs expressed by $\mathrm{CD} 4^{+} \mathrm{T}$-cells will result in an efficient inflammatory immune response and effector T-cell development (47). In B-cells, TLRs synergistically engage FcRs, which generate a distinct signal (47). Similar signaling events could occur in $\mathrm{CD}^{+}{ }^{+} \mathrm{T}$-cells that express FcRs. TLRs bind to pathogen-derived nucleic acids, which are taken up by the cells via endocytosis or autophagy and transferred to the endolysosomal compartment (48). Intracellular pathogenic challenge triggers the generation of Th1 and $\mathrm{CD}^{+} \mathrm{T}$-cell responses, which develop from the engagement of TLRs by pathogen-associated molecular patterns (PAMPs) and produce IL-12, a cytokine that drives IFN- $\gamma$ production in Th1 cells. Both ITAM and MyD88 signaling pathways converge after coactivation of FcRs and TLRs, resulting in an appropriate inflammatory response. Coactivation of FcRs by ICs and TLRs via damage-associated molecular pattern (DAMP) on infiltrating myeloid cells in joints of rheumatoid arthritis patients contributes to severity of the disease (47). ICs and PAMPs or DAMPs induce cross-talk and contribute to both the onset and the exacerbation of autoimmune disease (47). The nucleic acid-recognizing TLRs (NA-TLRs), also referred to as endosomal TLRs (TLR3, TLR7, TLR8, and TLR9), participate in an autoimmune response (20). The subcellular partitioning of TLRs, cytosolic vs. membrane, discriminates between self and altered non-self DNA and is a key mechanism for the development of autoimmunity (49). Fc $\gamma$ RIIIamediated signal in $\mathrm{CD}^{+}$T-cells upregulates NA-TLRs, which then colocalize with Fc $\gamma$ RIIIa, and some of these NA-TLRs move to the plasma membrane (Figure 2) (11). This is the evidence for FcR's role in modulating TLR signaling in $\mathrm{CD}^{+}{ }^{+} \mathrm{T}$-cells. FcyRIIIa-mediated signaling in $\mathrm{CD}^{+}{ }^{+} \mathrm{T}$-cells also upregulates MyD88 and HMGB1, the two proteins that are critical for TLR signaling and nucleic acid sensing (11). DNA-containing ICs in B-cells and pDCs trigger HMGB1-mediated TLR9 activation that contributes to autoimmune pathology (50). TLR agonists have been used to study TLR signaling events in $\mathrm{CD} 4^{+} \mathrm{T}$-cells (19). Surprisingly, various CpG oligodeoxynucleotides, a TLR9 ligand used to study both mouse and human $\mathrm{CD} 4^{+} \mathrm{T}$-cells, show a costimulatory activity that promotes polarization of different Th subsets (51). TLR9-deficient lpr/lpr mice show a selective defect in autoantibody production (52). DAMPs induce inflammatory $\mathrm{T}$ cell responses either directly or indirectly by inducing cytokine production from innate cells. TLR signaling overcomes a ratelimiting chromatin barrier from histone-containing nucleosomes that bind DNA, suggesting its role in epigenetic modifications $(53,54)$. IFN- $\gamma$ cytokine is a key player in TLR signaling and chromatin remodeling, and it is produced from Fc $\gamma$ RIIIa signaling in CD4 ${ }^{+}$T-cells $(10,53)$. Observations over the last decade have also shown a DC subset-specific expression of PRRs and cytokines produced by these cells promote the differentiation of T-cells into effector populations (55). Emerging evidence suggests that both FcR and TLR signaling trigger $\mathrm{CD}^{+}{ }^{+} \mathrm{T}$-cell-mediated proinflammatory responses. How these signals together influence the development of effector T-cells and/or their contribution to the expansion of memory T-cell pool will be of interest.

\section{FcRs AND NUCLEIC ACID SENSING}

Nucleic acid-recognizing TLRs primarily reside intracellularly in endosomes. This prevents recognition of self nucleic acids by the host. Internalization of RNA- or DNA-containing ICs by FcyRIIa and subsequent delivery of nucleic acids to endosomes results in an inappropriate IFN response $(20,23)$. Nucleic acid reaches the cytosolic compartment either via viral infection or by uptake of DNA/RNA-ICs. Thus, FcRs are crucial for the delivery of nucleic acids to the cytosol, where DNA sensing occurs (22). Nucleic acid-sensing pathways are the therapeutic targets in both autoimmunity and cancers (56). High mobility group box 1 (HMGB1) protein is crucial for the efficient delivery of self nucleic acids to TLR-containing endosomes (50, 57). HMGB1 associates with DNA-ICs and stimulates cytokine production via the TLR9-MyD88 pathway in pDCs (50). HMGB1 uses TLR2 and TLR4 as cellular receptors and engages $\mathrm{S} 100$ calcium binding protein A12 (RAGE) to produce type 1 IFN (58). The mechanism and route for RNA/DNA delivery to endolysosome or to the ER in $\mathrm{CD}^{+} \mathrm{T}$-cells are not yet recognized. Membrane Fc $\gamma$ RIIIa on activated $\mathrm{CD}^{+}{ }^{+} \mathrm{T}$-cells provides a possible route and mode of RNA/DNA-ICs internalization and delivery of the nucleic acids to the endosomes (Figure 2).

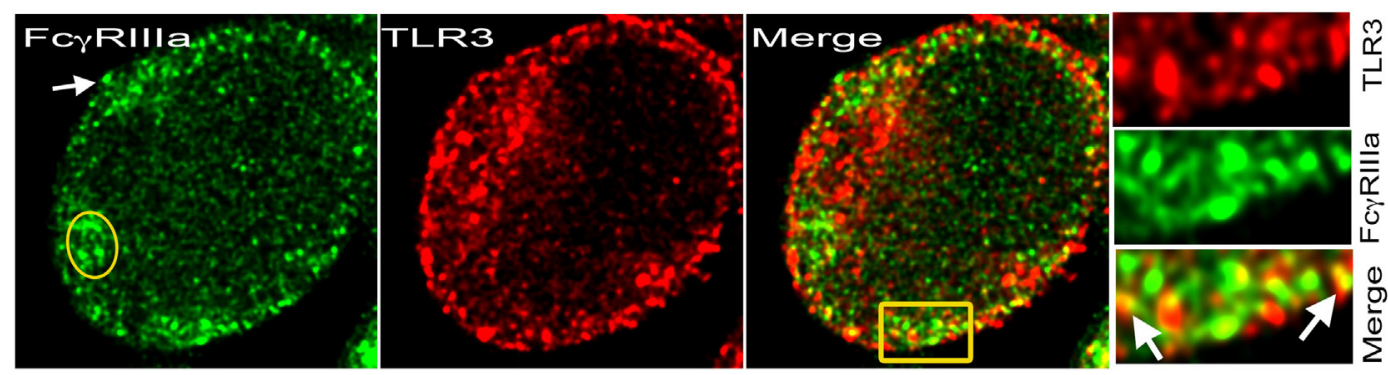

FIGURE 2 | TLR3 on cell membrane with Fc $\gamma$ RIIla. Stimulated emission depletion (STED) confocal image of a human CD4 ${ }^{+}$T-cell activated with plate-bound anti-CD3 + ICs + sublytic C5b-9 post 48 h. FcyRllla recognized by binding of Alexa Fluor 488-labeled ICs (green) and TLR3 with monoclonal antibody-Alexa Fluor 594 (red). At the plasma membrane, both proteins colocalized in many spots. IC binding showed cytosolic FcyRIlla (yellow oval) and on the plasma membrane (white arrow). Area amplified from merge shown in yellow rectangular. 
Nucleic acids activate immune cells to induce inflammation and immunity (22). Both TLRs and retinoic acid-inducible gene 1 (RIG-1)-like helicases participate in nucleic acid recognition. Immune sensing of DNA is observed both in early innate as well as late adaptive immune responses $(59,60)$. Aberrant DNA, altered self-DNA, and cyclic dinucleotide sensing by signaling proteins in the cytosol trigger DNA-signaling pathways. DNAICs and nucleosomes are closely associated with the development of inflammation in SLE. DNA-sensing proteins co-operate with TLRs to mount the immune challenge and discriminate against damaged DNA. ICs that stimulate B-cells contain DNA that is hypomethylated and such ICs modulate T-cell responses (61). Members of the $\mathrm{DExD} / \mathrm{H}$ box helicase family of proteins, such as RIG-1, interferon inducible helicase C (IFIH1/MDA5), and RIG-1-like receptor (LGP2) recognize cytosolic ssRNA and dsRNA and signal through mitochondrial antiviral signaling proteins to activate interferon regulatory factor (IRF) 1, IRF3, IRF7, and NF- $\kappa$ B. These, in turn, trigger expression of IFN- $\alpha$ and other pro-inflammatory cytokines (21). Fc $\gamma$ RIIIa engagement by ICs in $\mathrm{CD}^{+} \mathrm{T}$-cells enhances the expression of both IRF3 and IRF7. Fc $\gamma$ RIIIa expression by CD4 ${ }^{+}$T-cells opens up the possibility that the DNA-ICs bind to PHYIN (pyrin and HIN200) domain-containing family protein absent in melanoma 2 (AIM2) and to apoptosis-related speck protein (ASC), leading to the formation of inflammasome-like structures producing IL-1 $\beta$ in $\mathrm{CD}^{+}$T-cells. IC stimulation of human naive $\mathrm{CD} 4^{+} \mathrm{T}$-cells via Fc $\gamma$ RIIIa induces production of IL-1 $\beta$ (11). Thus, the expression of FcyRIIIa on activated CD4 ${ }^{+}$T-cells could be a crucial participant in the nucleic acid-signaling pathway.

\section{EPIGENETIC CHANGES IN CD4 ${ }^{+}$T-CELLS FROM Fc $\gamma$ RIIIa-Syk SIGNALING}

Epigenetic modifications are crucial for the differentiation and maintenance of $\mathrm{CD}^{+}$helper T-cell subsets. Acetylation and methylation of histones, which are considered epigenetic marks, are observed in SLE pathology. Both ifng and il17a promoters show epigenetic marks. Hypomethylation of $i l 4$ and il6 promoters are associated with disease activity (62). Even though a role for epigenetics in the differentiation of $\mathrm{CD} 4^{+} \mathrm{T}$-cell helper subsets is recognized, what drives these changes is unknown. In particular, it will be of interest to examine the mechanisms that drive epigenetic changes in the Bcl6 locus. Bcl6 is a transcription factor associated with the Tfh lineage that exhibits H3K4me3 marks, suggesting gene upregulation. Those genes that cause modification to histones and DNA show marked upregulation by F $\gamma$ RIIIa-pSyk signaling in naive $\mathrm{CD} 4^{+} \mathrm{T}$-cells. This signal also drives the differentiation of Th1, Th17, and Th subsets $(11,43,63)$. Our analysis of five donors for the genes associated with epigenetic chromatin modification showed a correlation among DNA (cytosine-5-)methyltransferase 1 (DNMT1), retinoblastoma-binding protein 7 (RBBP7), chromodomain helicase DNA-binding protein 4 (CHD4), and methyl-CpG-binding domain protein 2 (MBD2) (63). These enzymes are part of a histone deacetylase complex and are upregulated by the FcyRIIIa-pSyk signal. The SET domaincontaining lysine methyltransferases (SETD)-7 and SETD-2, which generate an $\mathrm{H} 3 \mathrm{~K} 4 \mathrm{me}$, and SETD-1 that generates a $\mathrm{H} 3 \mathrm{~K} 9$ methyl mark, were also significantly upregulated by FcyRIIIapSyk cosignaling compared to the canonical CD28 cosignal (63). $\mathrm{H} 3 \mathrm{~K} 4 \mathrm{mel}$ is enriched at poised or active genes and shown to be a marker of active enhancers in combination with H3K27ac and p300 binding (64). H3K27 hypomethylation and H3K18 hypermethylation are observed in activated naive $\mathrm{CD} 4^{+} \mathrm{T}$ cells and in SLE T-cells (65). These findings suggest that by upregulating DNA modification enzymes, the Fc $\gamma$ RIIIa-pSyk signal causes epigenetic changes in human $\mathrm{CD} 4^{+} \mathrm{T}$-cells. In Th1 cells, the ifng locus shows permissive histone modifications and DNA demethylation (66). In the promoter regions of 14,495 genes in SLE, CD4 ${ }^{+} \mathrm{T}$ cells, 236 were hypomethylated and 105 were hypermethylated (67). A profound hypomethylation of genes regulated by type I IFN was observed in genome-wide DNA methylation analysis (68). Methylation changes in SLE persist beyond flares for several months (68). SLE patients demonstrate the elevated presence of complement-opsonized ICs that engage membrane FcyRIIIa. Thus, it is plausible that the Fc $\gamma$ RIIIa-pSyk signal in CD4 ${ }^{+}$T-cells contributes to the modifications observed in the ifng and $i l 17 a$ promoters. DNA methyltransferase, Dnmt3a, establishes a genetically silent chromatin structure at the regulatory region of ifng locus by methylating DNA. It has been proposed that methylation at $-53 \mathrm{CpG}$ by Dnmt3a suppresses IFN- $\gamma$ transcription during Th2 development (69). FcyRIIIa-pSyk signaling suppresses Dnmt3a expression compared to CD28 signaling in CD $4^{+}$T-cells. This -53 region is also the preferred binding site for activation transcription factor (ATF)2. In our study, the Fc $\gamma$ RIIIa-Syk signal significantly upregulated the ATF2 gene expression, suggesting a possible role in increased IFN- $\gamma$ production (11). KAT6A is another lysine-transferase that was significantly upregulated by Fc $\gamma$ RIIIa-pSyk signaling. This gene is suggested to act as a coactivator of RUNX1, which drives Th17 differentiation. Children with a mutation in KAT6A show developmental disorders and cognitive defects (www.Chloekat6a.org). Decrease in DNMT expression results in hypomethylation of promoters of SLEassociated genes, which drives their overexpression. A positive correlation with DNMT1 and MBD2 expression is observed with disease activity in SLE patients $(70,71)$. Epigenetic changes not only regulate the differentiation of $\mathrm{CD} 4^{+} \mathrm{T}$-cells but also TLR signaling (72). CD4 ${ }^{+} \mathrm{T}$ cells express TLR4 (not a DNA sensor), which drives epigenetic regulation of the TNF- $\alpha$ promoter (73). Also, the pan-histone deacetylase inhibitor LBH589 represses cytokines IL-6, IL-10, IL-12, and IL-23 (74). Treatment of CD4 ${ }^{+}$ T-cells with demethylating agents (hydrazine, procainamide, and 5 -AzaC) renders them autoreactive. Adoptive transfer of such cells in mice causes them to produce anti-dsDNA antibodies and develop IC glomerulonephritis (75). These studies document a role for epigenetics in autoimmune pathology and data from our laboratory showed modulation of several enzymes that cause epigenetic modifications by Fc $\gamma$ RIIIa-pSyk signaling (63). It will be important to further investigate these mechanisms to understand and enhance the efficacy of demethylating agents for SLE therapy.

\section{CONCLUDING REMARKS}

Even though earlier studies documented the presence of low-affinity FcRs on $\mathrm{CD}^{+} \mathrm{T}$-cells, neglect in examining the 
contribution of these receptors in $\mathrm{CD}^{+} \mathrm{T}$-cell responses over the past two decades has hampered progress in establishing the contribution of FcRs to adaptive immune responses. Emerging data reconfirm some of the earlier findings that activated CD4 ${ }^{+} \mathrm{T}$-cells not only express FcRs, but signaling via these receptors modulates adaptive immune responses. Engagement of FcRs by the ligand contributes to the development of $\mathrm{CD} 4^{+}$effector T-cell responses. Low-affinity FcRs are critical for innate immune responses, and their presence on $\mathrm{CD} 4^{+} \mathrm{T}$-cells, cells of adaptive immunity, suggests their critical role in adaptive immunity. Cross-linking by complexed-Ig triggers proliferation of FcyRIIIa-bearing CD4 ${ }^{+}$ T-cells via receptor dimerization. The internalization of RNA/ DNA-ICs by Fc $\gamma$ RIIIa ${ }^{+} \mathrm{CD} 4^{+}$T-cells by engaging TLRs triggers signaling via DNA sensors. Whether these signaling events contribute to the development of IFN signature and plasma cell development will be important to understand the underlying mechanism of autoimmune pathology. It will be of further significant interest to explore whether induced expression of TLR proteins by Fc $\gamma$ RIIIa signaling generate a cross-talk with TLRs and enhance nucleic acid sensing. How these signals influence the fate of effector T-cells and contribute to the central memory pool is an important question. On memory recall, such cells will

\section{REFERENCES}

1. Sandor M, Lynch RG. Lymphocyte Fc receptors: the special case of T cells. Immunol Today (1993) 14:227-31. doi:10.1016/0167-5699(93)90168-K

2. Nimmerjahn F, Ravetch JV. Fcgamma receptors as regulators of immune responses. Nat Rev Immunol (2008) 8:34-47. doi:10.1038/nri2206

3. Qian D, Sperling AI, Lancki DW, Tatsumi Y, Barrett TA, Bluestone JA, et al. The gamma chain of the high-affinity receptor for IgE is a major functional subunit of the T-cell antigen receptor complex in gamma delta T lymphocytes. Proc Natl Acad Sci U S A (1993) 90:11875-9. doi:10.1073/pnas.90.24.11875

4. Shores E, Flamand V, Tran T, Grinberg A, Kinet JP, Love PE. Fc epsilonRI gamma can support T cell development and function in mice lacking endogenous TCR zeta-chain. J Immunol (1997) 159:222-30.

5. Liu CP, Lin WJ, Huang M, Kappler JW, Marrack P. Development and function of $\mathrm{T}$ cells in $\mathrm{T}$ cell antigen receptor/CD3 zeta knockout mice reconstituted with Fc epsilon RI gamma. Proc Natl Acad Sci U S A (1997) 94:616-21. doi:10.1073/pnas.94.2.616

6. Chauhan AK, Moore TL. Immune complexes and late complement proteins trigger activation of Syk tyrosine kinase in human CD4(+) T cells. Clin Exp Immunol (2012) 167:235-45. doi:10.1111/j.1365-2249.2011.04505.x

7. Latour S, Chow LM, Veillette A. Differential intrinsic enzymatic activity of Syk and Zap-70 protein-tyrosine kinases. J Biol Chem (1996) 271:22782-90. doi:10.1074/jbc.271.37.22782

8. Kurosaki T, Gander I, Ravetch JV. A subunit common to an IgG Fc receptor and the T-cell receptor mediates assembly through different interactions. Proc Natl Acad Sci U S A (1991) 88:3837-41. doi:10.1073/pnas.88.9.3837

9. Arase H, Suenaga T, Arase N, Kimura Y, Ito K, Shiina R, et al. Negative regulation of expression and function of Fc gamma RIII by CD3 zeta in murine NK cells. J Immunol (2001) 166:21-5. doi:10.4049/jimmunol.166.1.21

10. Chauhan AK, Chen C, Moore TL, DiPaolo RJ. Induced expression of FcgammaRIIIa (CD16a) on CD4+ $\mathrm{T}$ cells triggers generation of IFNgammahigh subset. J Biol Chem (2015) 290:5127-40. doi:10.1074/jbc. M114.599266

11. Chauhan AK, Moore TL, Bi Y, Chen C. FcgammaRIIIa-Syk co-signal modulates CD4+ T-cell response and up-regulates Toll-like receptor (TLR) expression. J Biol Chem (2016) 291:1368-86. doi:10.1074/jbc.M115.684795

12. Toong C, Adelstein S, Phan TG. Clearing the complexity: immune complexes and their treatment in lupus nephritis. Int J Nephrol Renovasc Dis (2011) 4:17-28. doi:10.2147/IJNRD.S10233 be able to provide B-cell help and drive them to differentiate into plasma B-cells. Understanding of the interactions among FcRs, TLRs, and/or TCR will assist in explaining autoimmune pathology.

\section{AUTHOR CONTRIBUTIONS}

The author confirms being the sole contributor of this work and approved it for publication.

\section{ACKNOWLEDGMENTS}

I would like to thank Dr. Ye Bi (member of my laboratory) for discussion of the work. I would also like to thank Dr. Richard DiPaolo, Department of Molecular Microbiology, and Dr. Joel Eissenberg, Department of Biochemistry, Saint Louis University School of Medicine, for critical review of the work.

\section{FUNDING}

This work was supported by National Institute of Health RO1 grant (A1098114) to AC.

13. Moore T, Ekworomadu CO, Eko FO, MacMillan L, Ramey K, Ananaba $\mathrm{GA}$, et al. Fc receptor-mediated antibody regulation of $\mathrm{T}$ cell immunity against intracellular pathogens. J Infect Dis (2003) 188:617-24. doi:10.1086/ 377134

14. Bergtold A, Desai DD, Gavhane A, Clynes R. Cell surface recycling of internalized antigen permits dendritic cell priming of B cells. Immunity (2005) 23:503-14. doi:10.1016/j.immuni.2005.09.013

15. Heesters BA, Chatterjee P, Kim YA, Gonzalez SF, Kuligowski MP, Kirchhausen $\mathrm{T}$, et al. Endocytosis and recycling of immune complexes by follicular dendritic cells enhances B cell antigen binding and activation. Immunity (2013) 38:1164-75. doi:10.1016/j.immuni.2013.02.023

16. Phan TG, Green JA, Gray EE, Xu Y, Cyster JG. Immune complex relay by subcapsular sinus macrophages and noncognate B cells drives antibody affinity maturation. Nat Immunol (2009) 10:786-93. doi:10.1038/ni.1745

17. Guilliams M, Bruhns P, Saeys Y, Hammad H, Lambrecht BN. The function of Fcgamma receptors in dendritic cells and macrophages. Nat Rev Immunol (2014) 14:94-108. doi:10.1038/nri3582

18. Shrivastav M, Niewold TB. Nucleic acid sensors and type I interferon production in systemic lupus erythematosus. Front Immunol (2013) 4:319. doi:10.3389/fimmu.2013.00319

19. Mills KH. TLR-dependent T cell activation in autoimmunity. Nat Rev Immunol (2011) 11:807-22. doi:10.1038/nri3095

20. Pelka K, Shibata T, Miyake K, Latz E. Nucleic acid-sensing TLRs and autoimmunity: novel insights from structural and cell biology. Immunol Rev (2016) 269:60-75. doi:10.1111/imr.12375

21. Desmet CJ, Ishii KJ. Nucleic acid sensing at the interface between innate and adaptive immunity in vaccination. Nat Rev Immunol (2012) 12:479-91. doi:10.1038/nri3247

22. Hornung V, Latz E. Intracellular DNA recognition. Nat Rev Immunol (2010) 10:123-30. doi:10.1038/nri2690

23. Reynolds JM, Dong C. Toll-like receptor regulation of effector T lymphocyte function. Trends Immunol (2013) 34:511-9. doi:10.1016/j.it.2013.06.003

24. Bruhns P, Jonsson F. Mouse and human FcR effector functions. Immunol Rev (2015) 268:25-51. doi:10.1111/imr.12350

25. Lanier LL, Kipps TJ, Phillips JH. Functional properties of a unique subset of cytotoxic CD3+ T lymphocytes that express Fc receptors for IgG (CD16/ Leu-11 antigen). J Exp Med (1985) 162:2089-106. doi:10.1084/jem.162.6.2089

26. Moretta L, Webb SR, Grossi CE, Lydyard PM, Cooper MD. Functional analysis of two human T-cell subpopulations: help and suppression of B-cell responses 
by T cells bearing receptors for IgM or IgG. J Exp Med (1977) 146:184-200. doi:10.1084/jem.146.1.184

27. Moretta L, Mingari MC, Moretta A, Fauci AS. Human lymphocyte surface markers. Semin Hematol (1982) 19:273-84.

28. Sandor M, Gajewski T, Thorson J, Kemp JD, Fitch FW, Lynch RG. CD4+ murine $\mathrm{T}$ cell clones that express high levels of immunoglobulin binding belong to the interleukin 4-producing T helper cell type 2 subset. J Exp Med (1990) 171:2171-6. doi:10.1084/jem.171.6.2171

29. Fridman WH, Golstein P. Immunoglobulin-binding factor present on and produced by thymus-processed lymphocytes (T cells). Cell Immunol (1974) 11:442-55. doi:10.1016/0008-8749(74)90042-2

30. Kinet JP. The gamma-zeta dimers of $\mathrm{FC}$ receptors as connectors to signal transduction. Curr Opin Immunol (1992) 4:43-8. doi:10.1016/0952-7915(92) 90122-U

31. Sandor M, Houlden B, Bluestone J, Hedrick SM, Weinstock J, Lynch RG. In vitro and in vivo activation of murine gamma/delta $\mathrm{T}$ cells induces the expression of IgA, IgM, and IgG Fc receptors. J Immunol (1992) 148:2363-9.

32. Hudrisier D, Clemenceau B, Balor S, Daubeuf S, Magdeleine E, Daeron M, et al. Ligand binding but undetected functional response of FcR after their capture by T cells via trogocytosis. J Immunol (2009) 183:6102-13. doi:10.4049/ jimmunol.0900821

33. Uciechowski P, Gessner JE, Schindler R, Schmidt RE. Fc gamma RIII activation is different in CD16+ cytotoxic T lymphocytes and natural killer cells. Eur J Immunol (1992) 22:1635-8. doi:10.1002/eji.1830220643

34. Noraz N, Schwarz K, Steinberg M, Dardalhon V, Rebouissou C, Hipskind R, et al. Alternative antigen receptor (TCR) signaling in $\mathrm{T}$ cells derived from ZAP-70-deficient patients expressing high levels of Syk. J Biol Chem (2000) 275:15832-8. doi:10.1074/jbc.M908568199

35. Grammatikos AP, Ghosh D, Devlin A, Kyttaris VC, Tsokos GC. Spleen tyrosine kinase (Syk) regulates systemic lupus erythematosus (SLE) T cell signaling. PLoS One (2013) 8:e74550. doi:10.1371/journal.pone.0074550

36. Tan SL, Liao C, Lucas MC, Stevenson C, DeMartino JA. Targeting the SYK-BTK axis for the treatment of immunological and hematological disorders: recent progress and therapeutic perspectives. Pharmacol Ther (2013) 138:294-309. doi:10.1016/j.pharmthera.2013.02.001

37. Harding FA, McArthur JG, Gross JA, Raulet DH, Allison JP. CD28-mediated signalling co-stimulates murine $\mathrm{T}$ cells and prevents induction of anergy in T-cell clones. Nature (1992) 356:607-9. doi:10.1038/356607a0

38. Bour-Jordan H, Esensten JH, Martinez-Llordella M, Penaranda C, Stumpf $\mathrm{M}$, Bluestone JA. Intrinsic and extrinsic control of peripheral T-cell tolerance by costimulatory molecules of the CD28/B7 family. Immunol Rev (2011) 241:180-205. doi:10.1111/j.1600-065X.2011.01011.x

39. den Braber I, Mugwagwa T, Vrisekoop N, Westera L, Mogling R, de Boer $\mathrm{AB}$, et al. Maintenance of peripheral naive $\mathrm{T}$ cells is sustained by thymus output in mice but not humans. Immunity (2012) 36:288-97. doi:10.1016/j. immuni.2012.02.006

40. Zastepa E, Fitz-Gerald L, Hallett M, Antel J, Bar-Or A, Baranzini S, et al. Naive CD4 T-cell activation identifies MS patients having rapid transition to progressive MS. Neurology (2014) 82:681-90. doi:10.1212/WNL. 0000000000000146

41. Chauhan AK, Moore TL. T cell activation by terminal complex of complement and immune complexes. J Biol Chem (2011) 286:38627-37. doi:10.1074/jbc. M111.266809

42. Bluestone JA. Mechanisms of tolerance. Immunol Rev (2011) 241:5-19. doi:10.1111/j.1600-065X.2011.01019.x

43. Chauhan AK, DiPaolo RJ, Moore TL. Generation of CD4+ follicular helper $\mathrm{T}$ cells by complement and immune complexes. Arthritis Rheum (2012) 64:978. doi:10.1002/art.37735

44. Cao X. Self-regulation and cross-regulation of pattern-recognition receptor signalling in health and disease. Nat Rev Immunol (2015) 16:35-50. doi:10.1038/nri.2015.8

45. Bakema JE, Tuk CW, van Vliet SJ, Bruijns SC, Vos JB, Letsiou S, et al. Antibody-opsonized bacteria evoke an inflammatory dendritic cell phenotype and polyfunctional Th cells by cross-talk between TLRs and FcRs. J Immunol (2015) 194:1856-66. doi:10.4049/jimmunol.1303126

46. den Dunnen J, Vogelpoel LT, Wypych T, Muller FJ, de Boer L, Kuijpers TW, et al. IgG opsonization of bacteria promotes Th17 responses via synergy between TLRs and FcgammaRIIa in human dendritic cells. Blood (2012) 120:112-21. doi:10.1182/blood-2011-12-399931

47. van Egmond M, Vidarsson G, Bakema JE. Cross-talk between pathogen recognizing Toll-like receptors and immunoglobulin Fc receptors in immunity. Immunol Rev (2015) 268:311-27. doi:10.1111/imr.12333

48. Blasius AL, Beutler B. Intracellular toll-like receptors. Immunity (2010) 32:305-15. doi:10.1016/j.immuni.2010.03.012

49. Barton GM, Kagan JC, Medzhitov R. Intracellular localization of Toll-like receptor 9 prevents recognition of self DNA but facilitates access to viral DNA. Nat Immunol (2006) 7:49-56. doi:10.1038/ni1280

50. Tian J, Avalos AM, Mao SY, Chen B, Senthil K, Wu H, et al. Toll-like receptor 9-dependent activation by DNA-containing immune complexes is mediated by HMGB1 and RAGE. Nat Immunol (2007) 8:487-96. doi:10.1038/ ni1457

51. Landrigan A, Wong MT, Utz PJ. CpG and non-CpG oligodeoxynucleotides directly costimulate mouse and human $\mathrm{CD} 4+\mathrm{T}$ cells through a TLR9and MyD88-independent mechanism. JImmunol (2011) 187:3033-43. doi:10.4049/jimmunol.1003414

52. Marshak-Rothstein A. Toll-like receptors in systemic autoimmune disease. Nat Rev Immunol (2006) 6:823-35. doi:10.1038/nri1957

53. Qiao Y, Giannopoulou EG, Chan CH, Park SH, Gong S, Chen J, et al. Synergistic activation of inflammatory cytokine genes by interferon-gamma-induced chromatin remodeling and toll-like receptor signaling. Immunity (2013) 39:454-69. doi:10.1016/j.immuni.2013.08.009

54. Foster SL, Hargreaves DC, Medzhitov R. Gene-specific control of inflammation by TLR-induced chromatin modifications. Nature (2007) 447:972-8. doi:10.1038/nature05836

55. Merad M, Sathe P, Helft J, Miller J, Mortha A. The dendritic cell lineage: ontogeny and function of dendritic cells and their subsets in the steady state and the inflamed setting. Annu Rev Immunol (2013) 31:563-604. doi:10.1146/ annurev-immunol-020711-074950

56. Junt $\mathrm{T}$, Barchet $\mathrm{W}$. Translating nucleic acid-sensing pathways into therapies. Nat Rev Immunol (2015) 15:529-44. doi:10.1038/nri3875

57. Yanai H, Ban T, Wang Z, Choi MK, Kawamura T, Negishi H, et al. HMGB proteins function as universal sentinels for nucleic-acid-mediated innate immune responses. Nature (2009) 462:99-103. doi:10.1038/nature08512

58. Park JS, Gamboni-Robertson F, He Q, Svetkauskaite D, Kim JY, Strassheim D, et al. High mobility group box 1 protein interacts with multiple Toll-like receptors. Am JPhysiol Cell Physiol (2006) 290:C917-24. doi:10.1152/ ajpcell.00401.2005

59. Ishii KJ, Coban C, Kato H, Takahashi K, Torii Y, Takeshita F, et al. A Toll-like receptor-independent antiviral response induced by double-stranded B-form DNA. Nat Immunol (2006) 7:40-8. doi:10.1038/ni1282

60. Iwasaki A, Medzhitov R. Control of adaptive immunity by the innate immune system. Nat Immunol (2015) 16:343-53. doi:10.1038/ni.3123

61. Sano H, Morimoto C. Dna isolated from DNA/anti-DNA antibody immune complexes in systemic lupus erythematosus is rich in guanine-cytosine content. J Immunol (1982) 128:1341-5.

62. Mi XB, Zeng FQ. Hypomethylation of interleukin- 4 and -6 promoters in $\mathrm{T}$ cells from systemic lupus erythematosus patients. Acta Pharmacol Sin (2008) 29:105-12. doi:10.1111/j.1745-7254.2008.00739.x

63. Chauhan AK. Immune complexes and complement mediate epigenetic changes and trigger TLR signaling in CD4+ T cells. Ann Rheum Dis (2015) 74:194-5. doi:10.1136/annrhemdis-2015-eular.4958

64. Heintzman ND, Hon GC, Hawkins RD, Kheradpour P, Stark A, Harp LF, et al. Histone modifications at human enhancers reflect global cell-type-specific gene expression. Nature (2009) 459:108-12. doi:10.1038/nature07829

65. Miao CG, Yang JT, Yang YY, Du CL, Huang C, Huang Y, et al. Critical role of DNA methylation in the pathogenesis of systemic lupus erythematosus: new advances and future challenges. Lupus (2014) 23:730-42. doi:10.1177/0961203314527365

66. Schoenborn JR, Dorschner MO, Sekimata M, Santer DM, Shnyreva M, Fitzpatrick DR, et al. Comprehensive epigenetic profiling identifies multiple distal regulatory elements directing transcription of the gene encoding interferon-gamma. Nat Immunol (2007) 8:732-42. doi:10.1038/ni1474

67. Jeffries MA, Sawalha AH. Epigenetics in systemic lupus erythematosus: leading the way for specific therapeutic agents. Int J Clin Rheumtol (2011) 6:423-39. doi:10.2217/ijr.11.32 
68. Absher DM, Li X, Waite LL, Gibson A, Roberts K, Edberg J, et al. Genomewide DNA methylation analysis of systemic lupus erythematosus reveals persistent hypomethylation of interferon genes and compositional changes to CD4+ T-cell populations. PLoS Genet (2013) 9:e1003678. doi:10.1371/ journal.pgen.1003678

69. Jones B, Chen J. Inhibition of IFN-gamma transcription by site-specific methylation during T helper cell development. EMBO J (2006) 25:2443-52. doi:10.1038/sj.emboj.7601148

70. Liu CC, Ou TT, Wu CC, Li RN, Lin YC, Lin CH, et al. Global DNA methylation, DNMT1, and MBD2 in patients with systemic lupus erythematosus. Lupus (2011) 20:131-6. doi:10.1177/0961203310381517

71. Balada E, Ordi-Ros J, Serrano-Acedo S, Martinez-Lostao L, Vilardell-Tarres M. Transcript overexpression of the MBD2 and MBD4 genes in CD4+ T cells from systemic lupus erythematosus patients. J Leukoc Biol (2007) 81:1609-16. doi:10.1189/jlb.0107064

72. Boi SK, Elsawa SF. Epigentic regulation of Toll-like receptor signaling. Med Epigenet (2013) 1:19-30. doi:10.1159/000353684

73. Sullivan KE, Reddy AB, Dietzmann K, Suriano AR, Kocieda VP, Stewart M, et al. Epigenetic regulation of tumor necrosis factor alpha. Mol Cell Biol (2007) 27:5147-60. doi:10.1128/MCB.02429-06
74. Song W, Tai YT, Tian Z, Hideshima T, Chauhan D, Nanjappa P, et al. HDAC inhibition by LBH589 affects the phenotype and function of human myeloid dendritic cells. Leukemia (2011) 25:161-8. doi:10.1038/leu. 2010.244

75. Quddus J, Johnson KJ, Gavalchin J, Amento EP, Chrisp CE, Yung RL, et al. Treating activated CD4+ T cells with either of two distinct DNA methyltransferase inhibitors, 5-azacytidine or procainamide, is sufficient to cause a lupuslike disease in syngeneic mice. J Clin Invest (1993) 92:38-53. doi:10.1172/ JCI116576

Conflict of Interest Statement: The author declares that the research was conducted in the absence of any commercial or financial relationships that could be construed as a potential conflict of interest.

Copyright (c) 2016 Chauhan. This is an open-access article distributed under the terms of the Creative Commons Attribution License (CC BY). The use, distribution or reproduction in other forums is permitted, provided the original author(s) or licensor are credited and that the original publication in this journal is cited, in accordance with accepted academic practice. No use, distribution or reproduction is permitted which does not comply with these terms. 